\title{
Left Ventricular Dysfunction: The Perspective of Echocardiography in Ghana
}

\author{
Isaac Kofi Owusu ${ }^{1}$, Yaw Amo Wiafe ${ }^{2}$ \\ ${ }^{1}$ Department of Medicine, School of Medical Sciences, College of Health Sciences, Kwame Nkrumah University of Science and \\ Technology, Kumasi, Ghana \\ ${ }^{2}$ Department of Medical Diagnostics, College of Health Sciences, Kwame Nkrumah University of Science and Technology, \\ Kumasi, Ghana \\ Email: ^ikeowusu@yahoo.com
}

How to cite this paper: Owusu, I.K. and Wiafe, Y.A. (2019) Left Ventricular Dysfunction: The Perspective of Echocardiography in Ghana. World Journal of Cardiovascular Diseases, 9, 639-648. https://doi.org/10.4236/wjcd.2019.99057

Received: July 26, 2019

Accepted: September 3, 2019

Published: September 6, 2019

Copyright (c) 2019 by author(s) and Scientific Research Publishing Inc. This work is licensed under the Creative Commons Attribution International License (CC BY 4.0).

http://creativecommons.org/licenses/by/4.0/

(c) (i) Open Access

\begin{abstract}
Introduction: Ghana is one of the fastest growing economies in sub-Saharan Africa which is expected to undergo a significant epidemiologic transition because of industrialisation and economic development. Having transitioned from low to middle income status recently, this study investigated the epidemiology of left ventricular dysfunction (LVD) in patients who were referred for echocardiography. Material and Methods: We conducted a retrospective cross-sectional study on an out-patient population who were referred to the Precise Specialist Clinic in Kumasi, Ghana for echocardiography, from January 2016 to December 2018. Descriptive statistical analyses were performed and the results summarised in the proportions, tables and pie charts. Categorical variables and proportions were compared using Fisher's exact test and test of proportions respectively. P-value $<0.05$ was considered to be statistically significant. Results: The results show that $61 \%$ of the out-patient population referred for echocardiography between 2016 and 2018 had LVD at a mean age of 59 years. In this LVD population, Heart Failure with preserved ejection fraction $(\mathrm{HFpEF})$ and Heart Failure with reduced ejection fraction (HFrEF) accounted for $73 \%$ and $27 \%$ respectively. The majority of patients with HFrEF also had left ventricular diastolic dysfunction, mitral regurgitation and tricuspid regurgitation. Conclusion: This study shows that, HFpEF was seen in over $70 \%$ of patients with LVD, and it occurred at a relatively younger age. Efforts should be made for prevention, early detection and control of conditions such as hypertension, diabetes and obesity which have been shown to be associated with HFpEF.
\end{abstract}

\section{Keywords}

Left Ventricular Dysfunction, Heart Failure with Preserved Ejection 
Fraction, Systolic Dysfunction, Ghana

\section{Introduction}

Heart failure is a global health problem affecting over 26 million people worldwide, with sub-Saharan Africa (SSA) having the highest mortality rate of $34 \%$ [1]. Over the past decades, heart failure in SSA followed a unique trend, frequently associated with left ventricular systolic dysfunction (LVSD), with the commonest underlying conditions being hypertension, rheumatic heart disease, and cardiomyopathy [2] [3] [4]. However, heart failure in SSA is expected to undergo a significant epidemiologic transition by 2030, because of industrialisation and economic development [5]. The projected change in epidemiologic transition would reflect the increasing life expectancy and the adoption of detrimental lifestyles which were previously alien to SSA [6] [7].

In relation to the epidemiologic transition, recent data suggest that heart failure with preserved ejection fraction is becoming more common in SSA like the developed world [6] [8] [9]. Heart failure with preserved ejection fraction (HFpEF) refers to left ventricular diastolic dysfunction (LVDD) in a heart failure patient who maintains a normal left ventricular ejection fraction (LVEF) of $>50 \%$. While heart failure with reduced ejection (HFrEF) is widely known to be related to LVSD and has well documented treatment options, the management of HFpEF is non-specific and dependent on the underlying condition [10]. Recent studies have confirmed that comorbidities associated with HFpEF include chronic hypertension, obesity and diabetes which are on the rise in SSA and poorly managed in many patients [11] [12]. The rising prevalence of HFpEF may therefore reflect how well underlying comorbidities are being managed in SSA. However, knowledge on the characteristics of HFpEF versus HFrEF in middle-income and low-income countries remain scanty [13]. Given the persistently high mortality rate from heart failure in SSA [1] [14], adequate knowledge on the current epidemiology of left ventricular dysfunction (LVD), including the prevalence of HFpEF and HFrEF, can be helpful to targeting prevention and intervention strategies that could minimize mortality rate.

Transthoracic echocardiography is a good investigation tool for assessing HFpEF and HFrEF which was rarely used in SSA for the investigation and diagnosis of heart failure until recently. In particular, the diagnosis of HFpEF has so many confounders and requires a much more objective method [11]. Existing data on the prevalence of heart failure in most SSA countries were reported before Tissue Doppler Imaging (TDI) became common. As a result, the prevalence of $\mathrm{HFpEF}$ and $\mathrm{HFrEF}$ were either not reported, or determination of HFpEF was based on only pulsed wave (PW) Doppler which is limited in terms of differentiating normal diastolic function from pseudo-normalization in individuals who have moderate elevation of filling pressure [15]. 
The purpose of this study, therefore, was to assess the epidemiology of LVD in Ghana, using current standards of echocardiography. Ghana is one of the fastest growing economies in SSA which recently transitioned from low to middle income country. An evaluation on epidemiologic status of LVD in the out-patient population was therefore necessary.

\section{Methodology}

We conducted a retrospective cross-sectional study on an out-patient population who were referred to the Precise Specialist Clinic in Kumasi, Ghana for echocardiography, from January 2016 to December 2018. The study included all patients aged $\geq 15$ years, who were referred for echocardiography.

Kumasi is the second largest city in Ghana with a population of over 4 million. As a cosmopolitan society, it has a wide range of the inhabitants from all walks of life. The echocardiography laboratory of this clinic is opened to referrals from all physicians in public and private practice. It therefore serves as a major referral centre for the northern part of Ghana.

A comprehensive transthoracic echocardiographic examination was performed on all out-patient referrals, using GE Vivid S5 Ultrasound machine equipped with 3 - $5 \mathrm{MHz}$ sector transducer. All patients were examined in the left lateral decubitus position. The standard scanning planes for assessing left ventricular (LV) function were obtained, including the parasternal long and short axes views, the apical views and the subcostal view. Three LV short-axis views (basal, middle, and apical) and all standard LV apical views (4-, 2-, 3-chamber views) were acquired. M-mode, 2D, colour Doppler, PW Doppler and TDI were obtained in all patients. Image acquisition was obtained during held end-expiration to minimize cardiac respiratory motion.

Quantitative assessment of left ventricular systolic function was based on the parasternal long axis measurements of the ventricular dimensions, intraventricular septum, and left ventricular posterior wall which were used in calculating the ejection fraction in accordance with the Teichholz's method. Systolic dysfunction was then determined by an ejection fraction of $<50 \%$, which was further classified as mildly reduced ejection fraction (i.e. $40 \%-49 \%$ ) and significantly reduced ejection fraction $(<40 \%)$.

Assessment of diastolic function was based on the PW Doppler and TDI which were obtained from the annulus of the mitral valve in the apical 4-chamber view. PW Doppler was used in assessing the mitral valve inflow pattern which obtained the peak of passive filling (E wave) and the peak of active filling (A wave) for the calculation of E/A ratio. Deceleration time (DT) of the E wave was also measured along with the isovolumic relaxation time. TDI was performed in the apical views to obtain mitral annular velocities for the $\mathrm{E} / \mathrm{e}^{\prime}$ ratio calculation. Diastolic dysfunction was determined by an E/A ratio of $<1$ or $>2$, and E/e' ratio of $>9$.

Colour Doppler was also used in assessing the mitral and tricuspid valves to determine the presence or absence of regurgitation. Morphology of the valves 
were also assessed on greyscale.

Approval for the study was obtained from the Committee on Human Research, Publications and Ethics of the Kwame Nkrumah University of Science and Technology and KomfoAnokye Teaching Hospital.

\section{Statistical Analysis}

Data was double-entered into a Microsoft Excel Spread Sheet and exported to Stata version 14.1 (StataCorp, Texas, USA) for statistical analysis. Descriptive statistical analyses were performed and the results summarised in the proportions, tables and a pie chart. Categorical variables and proportions were compared using Fisher's exact test and test of proportions respectively. P-value < 0.05 was considered to be statistically significant.

\section{Results}

Altogether, 594 individuals were referred for echocardiography from January 2016 and December 2018. Table 1 shows the demographic characteristics of the population. Gender and age were fairly distributed below age 70, with a significant female dominance at age 70 and above. Over 60\% (367/594) of the population were above 50 years.

LVD was detected in 364 individuals, which represent $61.3 \%$ of the study population (average age: 59.4 years \pm 15.1 ). Other findings include: dilated left ventricle, dilated left atrium, concentric left ventricular hypertrophy, mitral regurgitation (MR), and tricuspid regurgitation (TR) as shown in Table 2.

LVSD was found in $16.5 \%$ (98/594) of the population (average age: 57.9 years $\pm 17.0)$, including $5.4 \%(32 / 594)$ with mildly reduced ejection fraction and $11.1 \%$ (66/594) with significantly reduced ejection fraction. Most individuals with LVSD also had MR (79.0\%) and TR (74.5\%). LVSD was also significantly associated with dilated left ventricle and dilated left atrium as shown in Table 3.

Table 1. Age and gender distribution of study population.

\begin{tabular}{|c|c|c|c|c|c|c|c|}
\hline \multirow[t]{2}{*}{ Gender } & \multicolumn{3}{|c|}{ Total } & \multicolumn{4}{|c|}{ Age group } \\
\hline & & & $<30$ & $30-49$ & $50-69$ & $70-89$ & $\geq 90$ \\
\hline \multicolumn{8}{|l|}{ Male } \\
\hline & Frequency & 296 & 27 & 91 & 137 & 39 & 2 \\
\hline & Percentage & $49.8 \%$ & $52.9 \%$ & $51.7 \%$ & $53.1 \%$ & $37.5 \%$ & $40.0 \%$ \\
\hline \multicolumn{8}{|l|}{ Female } \\
\hline & Frequency & 298 & 24 & 85 & 121 & 65 & 3 \\
\hline & Percentage & $50.2 \%$ & $47.1 \%$ & $48.3 \%$ & $46.9 \%$ & $62.5 \%$ & $60.0 \%$ \\
\hline & Total (\%) & $594(100 \%)$ & $51(100 \%)$ & $176(100 \%)$ & $258(100 \%$ & $104(100 \%)$ & $5(100 \%)$ \\
\hline & \multicolumn{7}{|c|}{$\mathrm{p}$-value $=0.089$} \\
\hline
\end{tabular}


Table 2. Left ventricular dysfunction and associated factors.

\begin{tabular}{cccccccccc}
\hline Characteristics & Dilated & Concentric & Dilated & MR & MS & AR & AS & TR & PR \\
\hline & LV & LVH & Left & N (\%) & N (\%) & N (\%) & N \% & N (\%) & N (\%) \\
\hline & N (\%) & N (\%) & Atrium & & & & & \\
\hline Notal Participants & $89(15.0)$ & $308(51.9)$ & $147(24.7)$ & $143(25.0)$ & $3(0.5)$ & $35(5.9)$ & $4(0.7)$ & $193(32.5)$ & $59(9.9)$ \\
Normal LV Function & $8(3.5)$ & $68(29.6)$ & $25(10.9)$ & $22(10.0)$ & $0(0.0)$ & $5(2.2)$ & $0(0.0)$ & $63(27.4)$ & $12(5.2)$ \\
LVD & $81(22.3)$ & $240(65.9)$ & $122(33.5)$ & $121(34.3)$ & $3(0.8)$ & $30(8.2)$ & $4(1.1)$ & $130(35.7)$ & $47(12.9)$ \\
LVSD & $68(69.4)$ & $49(50.0)$ & $63(64.3)$ & $77(79.0)$ & $0(0.0)$ & $15(15.3)$ & $2(2.0)$ & $73(74.5)$ & $29(29.6)$ \\
LVDD & $69(20.1)$ & $228(66.3)$ & $109(31.7)$ & $106(31.8)$ & $3(0.9)$ & $27(7.8)$ & $4(1.2)$ & $117(34.0)$ & $43(12.5)$ \\
\hline
\end{tabular}

Table 3. Echocardiography findings associated with (LVSD).

\begin{tabular}{|c|c|c|c|c|c|}
\hline \multicolumn{2}{|c|}{ RISK FACTOR } & YES & NO & TOTAL & P-VALUE \\
\hline & & $\mathrm{N}(\%)$ & $\mathrm{N}(\%)$ & $\mathrm{N}(\%)$ & \\
\hline \multicolumn{6}{|c|}{ 1) Left Ventricular Systolic Dysfunction LVSD } \\
\hline \multirow[t]{2}{*}{ Sex: } & Male & $50(51.0)$ & $246(49.6)$ & $296(49.8)$ & \\
\hline & Female & $48(49.0)$ & $250(50.4)$ & $298(50.2)$ & 0.797 \\
\hline \multirow[t]{5}{*}{ Age group: } & $<30$ & $6(6.1)$ & $45(9.1)$ & $51(8.6)$ & \\
\hline & $30-49$ & $23(23.5)$ & $153(30.8)$ & $176(29.6)$ & \\
\hline & $50-69$ & $43(43.9)$ & $215(43.3)$ & $258(43.4)$ & \\
\hline & $70-89$ & $25(25.5)$ & $79(15.9)$ & $104(17.5)$ & \\
\hline & $\geq 90$ & $1(1.0)$ & $4(0.8)$ & $5(0.8)$ & 0.154 \\
\hline \multirow[t]{2}{*}{ Dilated LV: } & Yes & $68(69.4)$ & $21(4.2)$ & $89(15.0)$ & \\
\hline & No & $30(30.6)$ & $475(95.8)$ & $505(85.0)$ & $<0.0001$ \\
\hline \multirow[t]{2}{*}{ LVH: Yes ...... } & Yes & $49(50.0)$ & $259(52.2)$ & $308(51.9)$ & \\
\hline & No & $49(50.0)$ & $237(47.8)$ & $286(48.1)$ & 0.688 \\
\hline \multirow[t]{2}{*}{ Dilated Left Atrium: } & Yes & $63(64.3)$ & $84(16.9)$ & $147(24.7)$ & \\
\hline & No & $35(35.7)$ & $412(83.1)$ & $447(75.3)$ & $<0.0001$ \\
\hline
\end{tabular}

2) Left Ventricular Diastolic Dysfunction (LVDD):

\begin{tabular}{cccccc} 
Sex: & Male & $167(48.5)$ & $129(51.6)$ & $296(49.8)$ & \\
& Female & $177(51.5)$ & $121(48.4)$ & $298(50.2)$ & 0.462 \\
Age group: & $<30$ & $13(3.8)$ & $38(15.2)$ & $51(8.6)$ & \\
& $30-49$ & $66(19.2)$ & $110(44.0)$ & $176(29.6)$ & \\
& $50-69$ & $183(53.2)$ & $75(30.0)$ & $258(43.4)$ & \\
& $70-89$ & $81(23.5)$ & $23(9.2)$ & $104(17.5)$ & \\
& $\geq 90$ & $1(0.3)$ & $4(1.6)$ & $5(0.8)$ & $<0.0001$ \\
Dilated LV: & Yes & $69(20.1)$ & $20(8.0)$ & $89(15.0)$ & \\
& No & $275(79.9)$ & $230(92.0)$ & $505(85.0)$ & $<0.0001$ \\
LVH & Yes & $228(66.3)$ & $80(32.0)$ & $308(51.9)$ & \\
& No & $116(33.7)$ & $170(68.0)$ & $286(48.1)$ & $<0.0001$ \\
Dilated left atrium & Yes & $109(31.7)$ & $38(15.2)$ & $147(24.7)$ & \\
& No & $235(68.3)$ & $212(84.8)$ & $447(75.3)$ & $<0.0001$ \\
\hline
\end{tabular}


The total population with LVDD was $57.9 \%$ (average age: 59.4 years \pm 14.9 ). LVDD was predominant in individuals above 50 years, with 44.6\% (265/594) individuals above 50 years having LVDD. Again, out of a total of 367 subjects above 50 years, the prevalence of LVDD was 72\% (265/367). Echocardiography findings that were associated with LVDD included dilated left ventricle, dilated left atrium, and concentric left ventricular hypertrophy as shown in Table 3.

Again, the total population with both LVSD and LVDD was 13.1\% (see Figure 1). Hence, the prevalence of HFpEF and HFrEF were $44.8 \%$ and $16.5 \%$ respectively, which yielded the total of $61.3 \%$ prevalence of LVD in the entire echocardiography out-patient population.

Lastly, the LVD population which comprised of 364 out-patients had $73 \%$ (266/364) with HFpEF and 27\% (98/364) with HFrEF.

\section{Discussion}

The purpose of this study was to investigate the epidemiology of LVD in patients who were referred for echocardiography in an out-patient setting in Ghana. The results show that $61 \%$ of the outpatient population referred for echocardiography between 2016 and 2018 had LVD at a mean age of 59 years. In this LVD population, HFpEF and HFrEF accounted for $73 \%$ and $27 \%$ respectively. The mean age of patients in this study is consistent with the mean age of heart failure reported by previous studies in Ghana [4] [9] [14]. Amoah and Kallen [16], reported a lower mean age of 42 years in Accra, Ghana because their study included both children and adults. Various studies in the SSA have reported mean age of heart failure between 50 - 60 years [17]-[23]. This shows that heart failure is seen about two decades earlier in SSA populations than in the developed countries [24].

This study has also shown that over $70 \%$ of LVD in the out-patient population in Ghana is due to HFpEF. This is higher than the findings of Bonsu et al. [14]

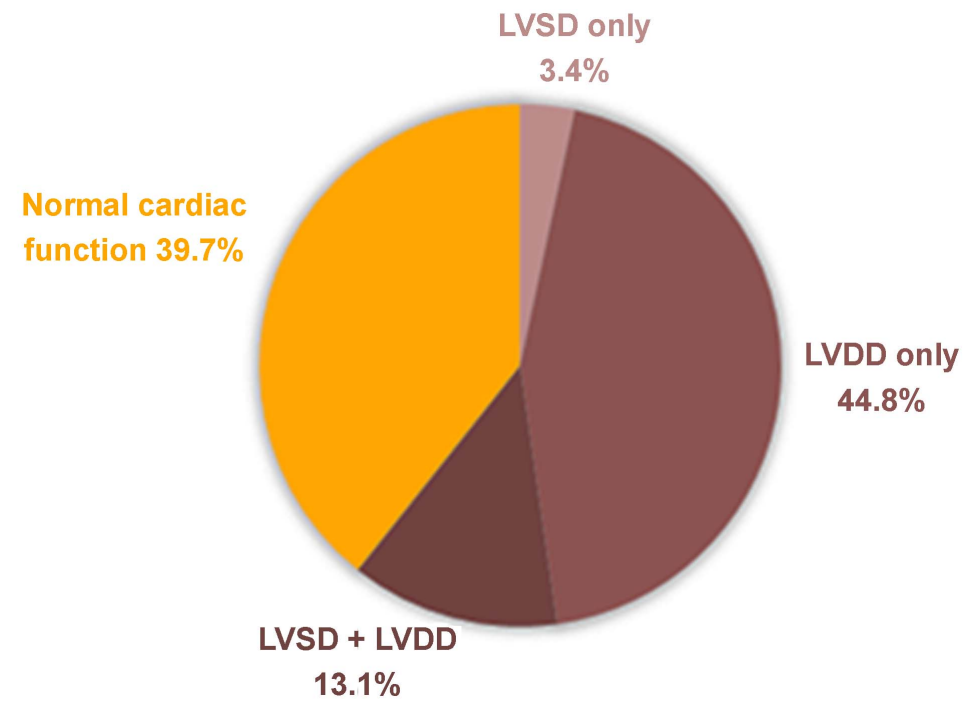

Figure 1. Percentage distribution of left ventricular dysfunction. 
and Abebe et al. [8] who reported $<60 \% \mathrm{HFpEF}$ in hospitalized patients in Ghana and Ethiopia respectively. However, it is also evident that their patients were not evaluated with TDI in the assessment of HFpEF; and as a result, patients with pseudo-normalization were not detected [15]. The over 70\% HFpEF in this population is the highest being reported by a study from SSA. It however agrees with Martínez-Braña et al. [25] and Kaneko et al. [26] who obtained similar percentages in Spain and Japan respectively, even though their HFpEF population were far older patients than the population in Ghana. It suggests that HFpEF occurs in SSA patients at a younger age than patients in the developed world where HFpEF is associated with older patients who are mostly women and living with chronic hypertension, diabetes or obesity [11]. In this Ghanaian study, the HFpEF population was rather younger, averagely less than 60 years old, and far below the mean age of 80 years reported by Martínez-Braña et al. [25] in Spain. However, it is known that blacks have a substantially higher risk for hypertension at a younger age than whites [27] which suggests that HFpEF in blacks may also be occurring at a younger age. Moreover, research has shown that although the prevalence of hypertension is declining in developed countries, the trend in SSA is rather on the rise [28] and poorly controlled, with several cases of hypertension undetected [29]. The increasing burden of hypertension obviously makes inhabitants of this region susceptible to HFpEF. Efforts should be made for prevention, early detection and control of hypertension, diabetes and obesity which have been shown to be associated with HFpEF [11].

On the other hand, HFrEF in this population was less than a third of LVD cases. This is lower than previous reports by Owusu et al. [9] and Bonsu et al. [14] in Kumasi, Ghana. Patients with HFrEF tend to have severe symptoms, more likely to be hospitalized; and less likely to be seen in out-patient settings than patients with HFpEF. This might explain the lower prevalence rate of HFrEF seen in this study. Another noteworthy finding of the present study is that $79 \%$ of patients with HFrEF also had MR, a condition which is associated with poor long-term survival rate [30]. In addition, there was high percentage of left ventricular and left atrial dilation in relation to HFrEF in this population (see Table 2), which are usually associated with functional MR. Functional MR often develops in patients with severe systolic dysfunction [31] and that the high percentage of such cases in this population suggests that patients with HFrEF do not report early for treatment until the condition gets worse, leading to the higher likelihood of hospitalization with associated increased mortality rate [1].

The limitations of this study are that there were no provisions to follow-up on the outcome of these cases, as most of them were only referred for echocardiography.

\section{Conclusion}

In conclusion, HFpEF was seen in over $70 \%$ of patients with LVD in this study, and it occurred at a relatively younger age than those seen in developed countries. Efforts should be made for prevention, early detection and control of con- 
ditions such as hypertension, diabetes and obesity which have been shown to be associated with HFpEF. Early diagnosis and management of heart failure should therefore be promoted to minimize hospitalization and improve survival of patients with heart failure.

\section{Acknowledgements}

The authors would like to express their sincere gratitude to the management and staff of the Precise Specialist Clinic, Kumasi, Ghana for their support. Without their co-operation this study would not have been done.

\section{Data Availability}

The raw data used to support the findings of this study are available from the corresponding author upon reasonable request.

\section{Conflicts of Interest}

The authors declare that they have no conflicts of interest.

\section{References}

[1] Dokainish, H., Teo, K., Zhu, J., Roy, A., Al Habib, K.F., El Sayed, A., Palileo-Villaneuva, L., Lopez-Jaramillo, P., Karaye, K., Yusoff, K. and Orlandini, A. (2017) Global Mortality Variations in Patients with Heart Failure: Results from the International Congestive Heart Failure (INTER-CHF) Prospective Cohort Study. The Lancet Global Health, 5, e665-e672.

[2] Bloomfield, G.S., Barasa, F.A., Doll, J.A. and Velazquez, E.J. (2013) Heart Failure in Sub-Saharan Africa. Current Cardiology Reviews, 9, 157-173. https://doi.org/10.2174/1573403X11309020008

[3] Agbor, V.N., Essouma, M., Ntusi, N.A., Nyaga, U.F., Bigna, J.J. and Noubiap, J.J. (2018) Heart Failure in Sub-Saharan Africa: A Contemporaneous Systematic Review and Meta-Analysis. International Journal of Cardiology, 257, 207-215. https://doi.org/10.1016/j.ijcard.2017.12.048

[4] Owusu, I.K. and Boakye, Y.A. (2013) Prevalence and Aetiology of Heart Failure in Patients Seen at a Teaching Hospital in Ghana. Journal of Cardiovascular Diseases \& Diagnosis, 1, 1-4. https://doi.org/10.4172/2329-9517.1000131

[5] Mensah, G.A. (2008) Ischaemic Heart Disease in Africa. Heart, 94, 836-843. https://doi.org/10.1136/hrt.2007.136523

[6] Gallagher, J., McDonald, K., Ledwidge, M. and Watson, C.J. (2018) Heart Failure in Sub-Saharan Africa. Cardiac Failure Review, 4, 21-24. https://doi.org/10.15420/cfr.2018:4:1

[7] Churchill, L.O. (2013) Epidemiology of Ischaemic Heart Disease in Sub-Saharan Africa. Cardiovascular Journal of Africa, 24, 34. https://doi.org/10.5830/CVJA-2012-071

[8] Abebe, T.B., Gebreyohannes, E.A., Tefera, Y.G. and Abegaz, T.M. (2016) Patients with HFpEF and HFrEF Have Different Clinical Characteristics but Similar Prognosis: A Retrospective Cohort Study. BMC Cardiovascular Disorders, 16, 232. https://doi.org/10.1186/s12872-016-0418-9

[9] Owusu, I.K., Adu-Boakye, Y. and Tetteh, L.A. (2014) Hypertensive Heart Failure in 
Kumasi, Ghana. Open Science Journal of Clinical Medicine, 2, 39-43.

[10] Ilieșiu, A.M. and Hodorogea, A.S. (2018) Treatment of Heart Failure with Preserved Ejection Fraction. In: Islam, M., Ed., Heart Failure: From Research to Clinical Practice. Advances in Experimental Medicine and Biology, Springer, Cham, 67-87. https://doi.org/10.1007/5584_2018_149

[11] Andersson, C. and Vasan, R.S. (2014) Epidemiology of Heart Failure with Preserved Ejection Fraction. Heart Failure Clinics, 10, 377-388. https://doi.org/10.1016/j.hfc.2014.04.003

[12] Price, A.J., Crampin, A.C., Amberbir, A., Kayuni-Chihana, N., Musicha, C., Tafatatha, T., Branson, K., Lawlor, D.A., Mwaiyeghele, E., Nkhwazi, L. and Smeeth, L. (2018) Prevalence of Obesity, Hypertension, and Diabetes, and Cascade of Care in Sub-Saharan Africa: A Cross-Sectional, Population-Based Study in Rural and Urban Malawi. The Lancet Diabetes \& Endocrinology, 6, 208-222. https://doi.org/10.1016/S2213-8587(17)30432-1

[13] Ziaeian, B. and Fonarow, G.C. (2016) Epidemiology and Aetiology of Heart Failure. Nature Reviews Cardiology, 13, 368-378. https://doi.org/10.1038/nrcardio.2016.25

[14] Bonsu, K.O., Owusu, I.K., Buabeng, K.O., Reidpath, D.D. and Kadirvelu, A. (2017) Clinical Characteristics and Prognosis of Patients Admitted for Heart Failure: A 5-Year Retrospective Study of African Patients. International Journal of Cardiology, 238, 128-135. https://doi.org/10.1016/j.ijcard.2017.03.014

[15] Oh, J.K. (2007) Echocardiography in Heart Failure: Beyond Diagnosis. European Journal of Echocardiography, 8, 4-14. https://doi.org/10.1016/j.euje.2006.09.002

[16] Amoah, A.G. and Kallen, C. (2000) Aetiology of Heart Failure as Seen from a National Cardiac Referral Centre in Africa. Cardiology, 93, 11-18. https://doi.org/10.1159/000006996

[17] Kingue, S., Dzudie, A., Menanga, A., Akono, M., Ouankou, M. and Muna, W. (2005) A New Look at Adult Chronic Heart Failure in Africa in the Age of the Doppler Echocardiography: Experience of the Medicine Department at Yaounde General Hospital. Annales de cardiologie et d angeiologie, 54, 276-283. https://doi.org/10.1016/j.ancard.2005.04.014

[18] Familoni, O.B., Olunuga, T.O. and Olufemi, B.W. (2007) A Clinical Study of Pattern and Factors Affecting Outcome in Nigerian Patients with Advanced Heart Failure. Cardiovascular Journal of Africa, 18, 308-311.

[19] Stewart, S., Wilkinson, D., Hansen, C., Vaghela, V., Mvungi, R., McMurray, J. and Sliwa, K. (2008) Predominance of Heart Failure in the Heart of Soweto Study Cohort: Emerging Challenges for Urban African Communities. Circulation, 118, 2360-2367. https://doi.org/10.1161/CIRCULATIONAHA.108.786244

[20] Ogah, O.S., Adegbite, G.D., Akinyemi, R.O., Adesina, J.O., Alabi, A.A., Udofia, O.I., Ogundipe, R.F. and Osinfade, J.K. (2008) Spectrum of Heart Diseases in a New Cardiac Service in Nigeria: An Echocardiographic Study of 1441 Subjects in Abeokuta. BMC Research Notes, 1, 98. https://doi.org/10.1186/1756-0500-1-98

[21] Onwuchekwa, A.C. and Asekomeh, G.E. (2009) Pattern of Heart Failure in a Nigerian Teaching Hospital. Vascular Health and Risk Management, 5, 745-750. https://doi.org/10.2147/VHRM.S6804

[22] Damasceno, A., Mayosi, B.M., Sani, M., Ogah, O.S., Mondo, C., Ojji, D., Dzudie, A., Kouam, C.K., Suliman, A., Schrueder, N. and Yonga, G. (2012) The Causes, Treatment, and Outcome of Acute Heart Failure in 1006 Africans from 9 Countries: Results of the Sub-Saharan Africa Survey of Heart Failure. Archives of Internal Medicine, 172, 1386-1394. 
[23] Kwan, G.F., Bukhman, A.K., Miller, A.C., Ngoga, G., Mucumbitsi, J., Bavuma, C., Dusabeyezu, S., Rich, M.L., Mutabazi, F., Mutumbira, C. and Ngiruwera, J.P. (2013) A Simplified Echocardiographic Strategy for Heart Failure Diagnosis and Management within an Integrated Noncommunicable Disease Clinic at District Hospital Level for Sub-Saharan Africa. JACC: Heart Failure, 1, 230-236. https://doi.org/10.1016/j.jchf.2013.03.006

[24] Sliwa, K., Davison, B.A., Mayosi, B.M., Damasceno, A., Sani, M., Ogah, O.S., Mondo, C., Ojji, D., Dzudie, A., Kouam Kouam, C. and Suliman, A. (2013) Readmission and Death after an Acute Heart Failure Event: Predictors and Outcomes in Sub-Saharan Africa: Results from the THESUS-HF Registry. European Heart Journal, 34, 3151-3159.

[25] Martínez-Braña, L., Mateo-Mosquera, L., Bermúdez-Ramos, M., García, M.D., Hernández, L.F., Ameijeiras, Á.H. and Lado, F.L. (2015) Clinical Characteristics and Prognosis of Heart Failure in Elderly Patients. Revista Portuguesa de Cardiologia, 34, 457-463. https://doi.org/10.1016/j.repce.2015.07.006

[26] Kaneko, H., Suzuki, S., Yajima, J., Oikawa, Y., Sagara, K., Otsuka, T., Matsuno, S., Kano, H., Uejima, T., Koike, A., Nagashima, K., et al. (2013) Clinical Characteristics and Long-Term Clinical Outcomes of Japanese Heart Failure Patients with Preserved versus Reduced Left Ventricular Ejection Fraction: A Prospective Cohort of Shinken Database 2004-2011. Journal of Cardiology, 62, 102-109. https://doi.org/10.1016/j.jjcc.2013.03.013

[27] Thomas, S.J., Booth, J.N., Dai, C., Li, X., Allen, N., Calhoun, D., Carson, A.P., Gidding, S., Lewis, C.E., Shikany, J.M. and Shimbo, D. (2018) Cumulative Incidence of Hypertension by 55 Years of Age in Blacks and Whites: The CARDIA Study. Journal of the American Heart Association, 7, e007988. https://doi.org/10.1161/JAHA.117.007988

[28] Zhou, B., Bentham, J., Di Cesare, M., Bixby, H., Danaei, G., Cowan, M.J., Paciorek, C.J., Singh, G., Hajifathalian, K., Bennett, J.E. and Taddei, C. (2017) Worldwide Trends in Blood Pressure from 1975 to 2015: A Pooled Analysis of 1479 Population-Based Measurement Studies with 19. 1 Million Participants. The Lancet, 389, 37-55. https://doi.org/10.1016/S0140-6736(16)31919-5

[29] Ataklte, F., Erqou, S., Kaptoge, S., Taye, B., Echouffo-Tcheugui, J.B. and Kengne, A.P. (2015) Burden of Undiagnosed Hypertension in Sub-Saharan Africa: A Systematic Review and Meta-Analysis. Hypertension, 65, 291-298. https://doi.org/10.1161/HYPERTENSIONAHA.114.04394

[30] Nasser, R., Van Assche, L., Vorlat, A., Vermeulen, T., Van Craenenbroeck, E., Conraads, V., Van der Meiren, V., Shivalkar, B., Van Herck, P. and Claeys, M.J. (2017) Evolution of Functional Mitral Regurgitation and Prognosis in Medically Managed Heart Failure Patients with Reduced Ejection Fraction. JACC: Heart Failure, 5, 652-659. https://doi.org/10.1016/j.jchf.2017.06.015

[31] Kaneko, H., Suzuki, S., Uejima, T., Kano, H., Matsuno, S., Takai, H., Oikawa, Y., Yajima, J., Aizawa, T. and Yamashita, T. (2014) Functional Mitral Regurgitation and Left Ventricular Systolic Dysfunction in the Recent Era of Cardiovascular Clinical Practice, an Observational Cohort Study. Hypertension Research, 37, 1082-1087. https://doi.org/10.1038/hr.2014.122 